\title{
Potential of Hard Candy Containing Spray-Dried Vernonia cinerea Extract with Total Phenolic Compounds, Total Flavonoids and Nicotine Replacement as an Anti-Smoking Aid
}

\author{
Rungtiwa Kanthain', Supawatchara Singhatong ${ }^{2}$, Surapol Natakankitkul ${ }^{3}$, Nathupakorn Dechsupa ${ }^{4}$, Jirakrit \\ Leelarungrayub ${ }^{5, *}$
}

Rungtiwa Kanthain', Supawatchara Singhatong ${ }^{2}$, Surapol Natakankitkul ${ }^{3}$, Nathupakorn Dechsupa ${ }^{4}$, Jirakrit Leelarungrayub ${ }^{5, *}$

'Movement and Exercise Sciences, Department of Physical Therapy, Faculty of Associated Medical Sciences, Chiang Mai University, Chiang Mai 50200, THAILAND. ${ }^{2}$ Division of Clinical Chemistry, Department of Medical Technology, Faculty of Associated Medical Sciences, Chiang Mai University, Chiang Mai 50200, THAILAND.

${ }^{3}$ Department of Pharmaceutical Sciences, Faculty of Pharmacy, Chiang Mai University, Chiang Mai 50200, THAILAND.

${ }^{4}$ Department of Radiologic Technology, Faculty of Associated Medical Sciences, Chiang Mai University, Chiang Mai 50200, THAILAND.

${ }^{5}$ Department of Physical Therapy, Faculty of Associated Medical Sciences, Chiang Ma University, Chiang Mai 50200, THAILAND.

\section{Correspondence}

Assoc. Prof. Jirakrit Leelarungrayub

110 Sripum, Muang district, Chaing Mai 50200, THAILAND.

Phone no: $(+66) 053949245$

Fax: (+66) 053946042

E-mail: donrawee.leela@cmu.ac.th

History

- Submission Date: 22-09-2019

- Review completed: 25-10-2019;

- Accepted Date: 04-11-2019.

DOI : 10.5530/pj.2020.12.7

Article Available online http://www.phcogj.com/v12/i1

Copyright

(C) 2019 Phcogj.Com. This is an openaccess article distributed under the terms of the Creative Commons Attribution 4.0 International license.

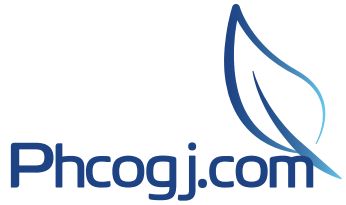

\begin{abstract}
Backgound: Vernonia cinerea (VC) is a natural plant claimed to reduce cigarette smoking. Some pilot anti-smoking products with nicotine replacement, such as lozenges or gum, have been presented, but with some adverse effects. Thus, application of VC as a new-anti-smoking product is very challenging. Objectives: The aims of this study were to compare the active compounds; total phenolic compounds, total flavonoids and nicotine, and study antioxidant activity on scavenging 2,2'-azino-bis (3-ethylbenzthiazoline-6-sulphonic acid) (ABTS) and 1,1-diphenyl-2-picryl hydrzayl (DPPH) radicals of extracts prepared by spray drying (SD) and freeze drying (FD) techniques for pilot hard candy. Methods: Raw VC materials of mixed parts, i.e., the stem, flowers and leaves, were made to form extracts by FD and SD techniques. Then, extract from the SD technique was manufactured industrially into hard candy containing glucose syrup and refined glucose. Total phenolic compounds, total flavonoids, nicotine, scavenging activity of extracts, VC hard candy and placebo candy were evaluated by folin-ciocalteau reagent, aluminum chloride colorimetric assay, high-performance liquid chromatography, ABTS cation decolorization and DPPH protocols. Results: Total phenolic compounds were significantly different between extracts, but total flavonoids and nicotine were slightly higher in SD extract. Antioxidant activity of both extracts on ABTS radicals was not significantly different, but the half-maximal inhibitory concentration (IC50) on DPPH radicals was significantly higher in SD extract when compared to the FD extract. Finally, total phenolic compounds, total flavonoids and nicotine, as well as scavenging activity could be detected in hard candy. Conclusion: VC can be used as an anti-smoking aid with nicotine replacement and anti-oxidant compounds in pilot hard candy.
\end{abstract}

Key words: Antioxidant activity, Nicotine, Total phenolic compounds, Total flavonoids, Vernonia cinerea, Hard candy.

\section{INTRODUCTION}

Smoking prevalence tends to be highest among people with the lowest levels of education and income, especially those living in low and middleincome countries. Therefore, current projections indicate that the number of smokers globally will increase to 1.6 billion over the next 25 years. ${ }^{1}$ Nevertheless, the overall number of cigarette smokers decreased from 12.2 million to 10.86 million between 1991 and 2007, but the number of younger men (aged around 18 years) and women (aged about 22 years) smokers increased. ${ }^{2}$ The Framework Convention of Tobacco Control (FCTC) from the World Health Organization (WHO), was the first international health treaty to be endorsed by 180 countries, including Thailand, and it reported an increased annual consumption by over 500 cigarettes per adult. ${ }^{3}$ Therefore, The Thai Health Professional Alliance against Tobacco (ThaiPAT) was established in late 2005 and has been campaigning since $2007 .{ }^{4}$ The Thai government has been campaigning for a reduction in smoking rate by providing various services such as behavioral counseling and/or suggestions on how to quit using the one-stop service or 1,600 telephone lines, as well as smoking cessation clinics in many hospitals. Previous evidence has shown that behavioral counseling with pharmacotherapy via nicotine replacement therapy (NRT) is successful, ${ }^{5,6}$ and using NRT increased the rate of smoking cessation by $50-70 \%{ }^{7}$ Unfortunately, there is not only the major disadvantage of highcost nicotine replacement, ${ }^{8}$ but also various adverse effects such as skin irritations, soreness of the mouth and throat, mouth ulcers, hiccups and coughing. ${ }^{9}$ Thus, natural plants can be developed for use instead of NRT, but there is less scientific evidence to support their effectiveness on smoking reduction. However, medicinal herbal tea from China, containing Eugenia aromaticum and Astragalus membranaceus Bunge, underwent a 4-week trial to reduce smoking withdrawal symptoms, and $38 \%$ of active smokers drinking the tea succeeded in smoking cessation. ${ }^{10}$ Furthermore, Vernonia cinerea (VC) in Thailand has been reported in Thai traditional medicine as an anti-smoking aid, and it has been studied in a special stop-smoking clinic at Thanyarak Institute in Pathumthani, Thailand. The results of a 14-day

Cite this article: Kanthain R, Singhatong S, Natakankitkul S, Dechsupa N, Leelarungrayub J. Potential of Hard Candy Containing Spray-Dried Vernonia cinerea Extract with Total Phenolic Compounds, Total Flavonoids and Nicotine Replacement as an Anti-Smoking Aid. Pharmacog J. 2020;12(1):35-43. 
VC tea supplementation program showed a higher abstinence rate (28.1\%) when compared to the control group (21.9\%). ${ }^{11}$ Moreover, condensed VC juice was studied preliminarily in light smokers and the results showed that the smoking rate for light cigarettes decreased by approximately $62.7 \%$ when compared to the control group $(14.04$ $\%)$, who received a smoking consultation program. ${ }^{12}$ In 2015, eight active compounds of three flavones and one flavonol were found in methanolic VC extract that possesses a strong inhibitory effect on the human cytochrome, P450 2A6 (CYP2A6); and monoamine oxidase (MAO-A and MAO-B), which functions on catalyzing nicotine and dopamine metabolisms, could have implications in combining drug therapy with smoking cessation. ${ }^{13}$ Whereas, the VC leaf extract from boiling water preparation showed interesting flavonols, flavones, nitrate or nitrite, and nicotine, ${ }^{14}$ as well as presenting antioxidant activity. ${ }^{14,15}$

Therefore, VC can be used for reducing cigarette smoking, especially the formula of $\mathrm{VC}$ condensed juice, which showed more potential benefits for the reduction the cigarette smoking than crude mixed VC dry materials in a tea bag. However, VC condensed juice is not suitable because it is difficult to prepare, therefore, new products such as lozenges, gum or candy should be manufactured under either pharmaceutical or industrial guidelines. Furthermore, the process of preserving active compounds in any materials can be performed with dry extract before mixing in lozenges, gum or candy, when compared to basic solution. In a previous review, the most frequent drying methods such as freeze, spray, spray freeze, and supercritical fluid drying, improved the stability and bioavailability of dry materials. ${ }^{16}$ Drying can be performed using evaporation mechanisms, such as vacuum or foam drying; evaporation and atomization pathways like spray drying (SD); sublimation mechanisms like freeze drying (FD); and spray freeze and supercritical fluid drying. ${ }^{17}$ When comparing between FD and SD, FD is suitable for processing temperature sensitivity, low temperature, higher yield and greater production, but SD is simple, convenient, and cost-effective with a short processing time. Whereas, spray freeze and supercritical fluid drying have very high cost. ${ }^{18}$ Therefore, spray drying was suitable for $\mathrm{VC}$ extract preparation before manufacturing the product. Unfortunately, the different contents of total phenolic compounds, total flavonoids and nicotine in extracts between freeze and spray drying were unclear. In addition, the final pilot product of hard candy prepared from industry must be evaluated, and also the antioxidant capacity on scavenging radicals; either the ABTS or 1,1-diphenyl-2-picryl hydrzayl (DPPH) cation, which was an aim of this study.

\section{MATERIALS AND METHODS}

\section{Extracts and product preparations}

The extract preparations followed those in a previous study. ${ }^{12}$ Prior to the start of this study on active smokers, raw materials of VC were purchased from an organic farm at Phitsanulok province, Thailand. With regard to safety guarantees in raw materials, mercury and zinc were analyzed by the In-house method TE-CH-260 in connection with AOAC (2016) 2013.06 and AOAC (2016) 999.10, in the same way that Tin is analyzed by the In-house method TE-CH-340 based on AOAC (2016) 985.16. at the Central Laboratory (Thailand) Co., Ltd. (Chaing Mai, Thailand). Twenty grams of whole plant parts; the stem, flowers and leaves, were dried in a heated oven and mixed with $350 \mathrm{~mL}$ of sterile water before boiling at 60 degrees Celsius. Finally, approximately $150 \mathrm{~mL}$ of condensed VC juice was filtered before the dry extracts were prepared by spray drying at the Argo-industrial Business Service Center, Faculty of Agro-industry, or by freeze drying at the Department of Clinical Chemistry, Faculty of Associated Medical Sciences, Chiang Mai University, Chiang Mai, Thailand.

Product preparation in industry depends on the preliminary results of total phenolic compounds and nicotine in extracts from either spray or freeze-drying techniques. The higher concentration of nicotine in extract was selected for making the pilot anti-smoking product, designed as hard candy. Standardized manufacturing of hard candy was performed under Certificate TH 14/7924 (TAS 9023-2007) GMP Codex Alimentarius, Recommended International Code of Practices, General Principles of Food Hygiene, CAC/RCP 1-1969, Rev.4 (2003) at the Healthy Bee Co., Ltd. (Chiang Mai, Thailand). The product was manufactured industrially as a pilot hard candy contained in a sealed candy panel. Each piece of pilot hard candy contained VC extract, glucose syrup (Capital Glucose Co., Ltd., Nakornpathom, Thailand) and refined sugar (Mitr Phol Sugar Corp., Ltd., Lampang, Thailand) at a suitable ratio, whereas the placebo candy had only glucose syrup and refined sugar. The production process involved dissolving ingredients and cooking before dehydrating and cooling, and kneading and molding the semi-product prior to sorting into hard candy. All of the processes were performed under sterile techniques in a clean factory. Finally, eight pieces of candy were packed into a sealed blister pack. The total phenolic compounds and nicotine content in the extracts and hard candy were evaluated in the same way as for scavenging radicals; the ABTS and DPPH radical assay.

\section{Total phenolic compound analysis}

The total content of phenolic compounds in the extracts, candy or placebo candy product was determined by the Singleton and Rossi method, ${ }^{19}$ in which $40 \mu \mathrm{L}$ of the samples, at 20,10 and $5 \mathrm{mg} / \mathrm{mL}$, was mixed with $1.8 \mathrm{~mL}$ of diluted Folin-Ciocalteau reagent $(10 \% \mathrm{v} / \mathrm{v})$ (Merck KGaA, Germany), and kept in the dark for $5 \mathrm{~min}$, before 1.2 $\mathrm{mL}$ of $(7.5 \%)$ sodium carbonate (Merck, Dermstadt) was added. After that, the tubes were incubated for $60 \mathrm{~min}$, and pellets removed by centrifugation at a speed of $10,000 \mathrm{rpm}$ for $3 \mathrm{~min}$, with the supernatant being read at $765 \mathrm{~nm}$ by spectrophotometry. The total phenolic content in $1 \mathrm{~g}$ of extract or one candy product was calculated by comparing with standard gallic acid (0.008-1.0 mg/mL) (Fluka, Switzerland).

\section{Total flavonoid content}

Total flavonoid content was measured using the aluminum chloride colorimetric assay, adapted from a previous protocol..$^{20}$ Aqueous FD and SD extracts at $20-500 \mathrm{mg} / \mathrm{mL}$ and the product or placebo product or different dilutions of standard quercetin solution $(4.7-75.0 \mathrm{mg} /$ $\mathrm{mL}$ ) (Aldrich, Germany) were added in $100 \mu \mathrm{L}$ of $10 \% \mathrm{AlCl}_{3}(\mathrm{BDH}$ PROLABO, Germany). Then, $100 \mu \mathrm{L}$ of sodium acetate $(1.0 \mathrm{~mol} / \mathrm{L})$ (Ajax Finechem Pty Ltd, Germany) was added to $2.8 \mathrm{~mL}$ of deionized water. After incubation and protection from light for $30 \mathrm{~min}$ at room temperature, absorbance was measured at $415 \mathrm{~nm}$ by spectrophotometry against a freshly prepared blank reagent. Total flavonoid content of the extracts was expressed as mg of standard quercetin (Sigma-Aldrich, Germany) in $1 \mathrm{~g}$ of extract, and one piece of hard candy or placebo.

\section{Nicotine assay}

The protocol for evaluating the ascorbic acid content in VC extracts was performed by high-performance liquid chromatography (HPLC) using a previously published method. ${ }^{21}$ Before analysis, the VC extracts from spray $(20 \mathrm{mg} / \mathrm{mL})$ or freeze drying $(20 \mathrm{mg} /$ $\mathrm{mL})$ techniques and the product or placebo $(50 \mathrm{mg} / \mathrm{mL})$ were dissolved in deionized water and filtered with a micro-filter $(0.45 \mu \mathrm{m})$ (Minisart, Germany). The analysis was performed in the experimental condition using a C18 reverse phase column (Eclipse Plus C18: $5 \mathrm{~m}$, $4.6 \times 250 \mathrm{~mm}$; Agilent, USA) under a mixed mobile solvent (Methanol and $0.1 \%$ Trifluoroacetic acid; 50:50, $v / v$ ) (HPLC Grade, Lab-Scan, Thailand). The flow rate was $1.0 \mathrm{~mL} / \mathrm{min}^{-1}$ and injection volume 20 $\mu \mathrm{L}$ for all of the analyses. The total run time was $15 \mathrm{~min}$ and retention time for peak nicotine at $2.67 \pm 0.01 \mathrm{~min}$, identified by a diode array 
detector (DAD) (SPD-MZOA, SHIMADZU, JAPAN) at $260 \mathrm{~nm}$. The concentration of nicotine in the extracts or products was represented by a comparison with $1 \mathrm{~g}$ of extracts or one piece of hard candy.

\section{Total antioxidant capacity}

The antioxidant capacity of extracts and products was evaluated following the ABTS cation radical assay. ${ }^{22}$ Total antioxidant capacity referred to scavenging activity in order to bleach the $\mathrm{ABTS}^{*+}$ cation radicals that were produced by reacting ABTS (CALBIOCHEM, Darmst adt, Germany) solution ( $14 \mathrm{mmol} / \mathrm{L})$, with $14 \mathrm{mmol} / \mathrm{L}$ of potassium persulfate (Merck KGaA, Darmstadt, Germany) in deionized water for $12 \mathrm{~h}$ in the dark. The stock $\mathrm{ABTS}^{*+}$ was diluted in deionized water in order to start absorbance of $0.70 \pm 0.02$ at $734 \mathrm{~nm}$ by spectrophotometer. Ten $\mu \mathrm{L}$ of extracts or products was added in $990 \mu \mathrm{L}$ of working $\mathrm{ABTS}^{++}$solution in a plastic cuvette (size $1.5 \mathrm{~mL}$ ), and gently alternated inversely 5 times before absorbance was read. The percentage reduction of absorbance by spectrophotometry was calculated. All of the tests were evaluated three times and averaged. Total antioxidant capacity results of extracts from spray and freeze drying at $1 \mathrm{~g}$, and products or placebo at one panel of hard candy, were represented by comparing with the standard gallic acid equivalent (GAE) (mg).

\section{DPPH scavenging assay}

The protocol for scavenging DPPH radicals was modified from a previous study. ${ }^{23}$ Free radical scavenging activity of different extracts from spray and freeze drying, and the product and placebo product were measured by DPPH. In brief, $0.1 \mathrm{mM}$ solution of DPPH in $100 \%$ methanol was prepared, with $200 \mu \mathrm{L}$ being added in $2.8 \mathrm{~mL}$ of methanol, before mixing $100 \mu \mathrm{L}$ of different extract concentrations of $0.312-5.0$ $\mathrm{mg} / \mathrm{mL}$ with $10-80 \mathrm{mg} / \mathrm{mL}$ of candy product or candy placebo. The mixture was shaken and allowed to stand at room temperature for 30 min in the dark before absorbance was measured at $515 \mathrm{~nm}$, using a spectrophotometer (UV-VIS Shimadzu). Quercetin was the reference standard compound used and the experiment was carried out in triplicate. The half-maximal inhibitory concentration (IC50) value between the extracts and products was presented after calculating the use of an exponential rise to maximal fit curve in the Sigma Plot Program version 11.0 (Germany).

\section{Statistical analysis}

All of the data presented the mean and standard deviation from triplicated evaluation, and the Two-independent $\mathrm{T}$ test was used for statistical analysis between extracts and products by the statistical package for social sciences software (SPSS) version. 10.0 (SPSS Inc, Chicago, IL, USA) for Windows at $\mathrm{p}$ less than 0.05. Moreover, the standard curves of total phenolic compounds, nicotine, \% ABTS cation radical reduction and IC50 were calculated by fit curve, with exponential rise to maximum curve in the Sigma Plot (version 11.0) (Germany).

\section{RESULTS}

\section{Extract preparation}

The results of safety from heavy metals in raw materials were unable to detect mercury, despite there being approximately $0.019 \mathrm{mg} / \mathrm{kg}$ of it, and approximately $34.42-44.36 \mathrm{mg} / \mathrm{kg}$ of Zinc $(\mathrm{Zn})$. The results of extract preparation showed that $40 \mathrm{~g}$ of $\mathrm{VC}$ dry parts were mixed in $700 \mathrm{~mL}$ of clean water and turned into dry extract by freeze drying techniques. The final yield was $6.37 \mathrm{~g}$. Whereas, the final spray-dried extracts of $2.38 \mathrm{~g}$ were prepared from a ratio of $280 \mathrm{~g}$ of VC dry raw materials per 4.9 liters of clean water, before boiling until the water evaporated to a condensed VC juice (2.4 liters).

\section{Total phenolic compounds, total flavonoids and nicotine in extracts}

The standard curve of gallic acid from the total phenolic assay presented an exponential rise to maximal response from 0.04 to $10 \mathrm{mg} /$ $\mathrm{mL}$ (Figure 1A). The result of total phenolic compound assay in $1 \mathrm{~g}$ of extracts from spray or freeze drying is presented in Figure 1B. There was no significant difference between the extracts $(14.42 \pm 0.28 \mathrm{mg}$ and $14.36 \pm 0.76 \mathrm{mg}$ gallic acid equivalent $)(\mathrm{p}=0.70)$.

The results of total flavonoids in extracts from spray and freeze drying compared with standard quercetin $(4.7-57 \mu \mathrm{g} / \mathrm{mL}$ ) (Figure $2 \mathrm{~A}$ ), and there was no statistical difference in total flavonoids between the extracts $(2.7 \pm 0.2 \mathrm{mg} / \mathrm{g}$ spray-dried extract and $2.63 \pm 0.24 \mathrm{mg} / \mathrm{g}$ freeze-dried extract) $(\mathrm{p}=0.873)$ (Figure 2B).

The result of nicotine analysis showed that a modified protocol was performed. The peak of standard nicotine presented at $2.76 \mathrm{~min}$ (Figure 3A) when applied in the HPLC system for $15 \mathrm{~min}$, which was the same for the nicotine peaks in extracts from spray (Figure 3C) and freeze (Figure 3D) drying at $2.76 \mathrm{~min}$. After injecting standard nicotine, an exponential rise to maximal responses from 0.098 to $1.56 \mathrm{mg} / \mathrm{mL}$ is presented in Figure 3B. The nicotine concentration in extracts from spray and freeze drying at $1 \mathrm{~g}$ was insignificantly different at $28.99 \pm$ $0.28 \mathrm{mg}$ and $26.82 \pm 0.32 \mathrm{mg}$, respectively $(\mathrm{p}=1.00)$.

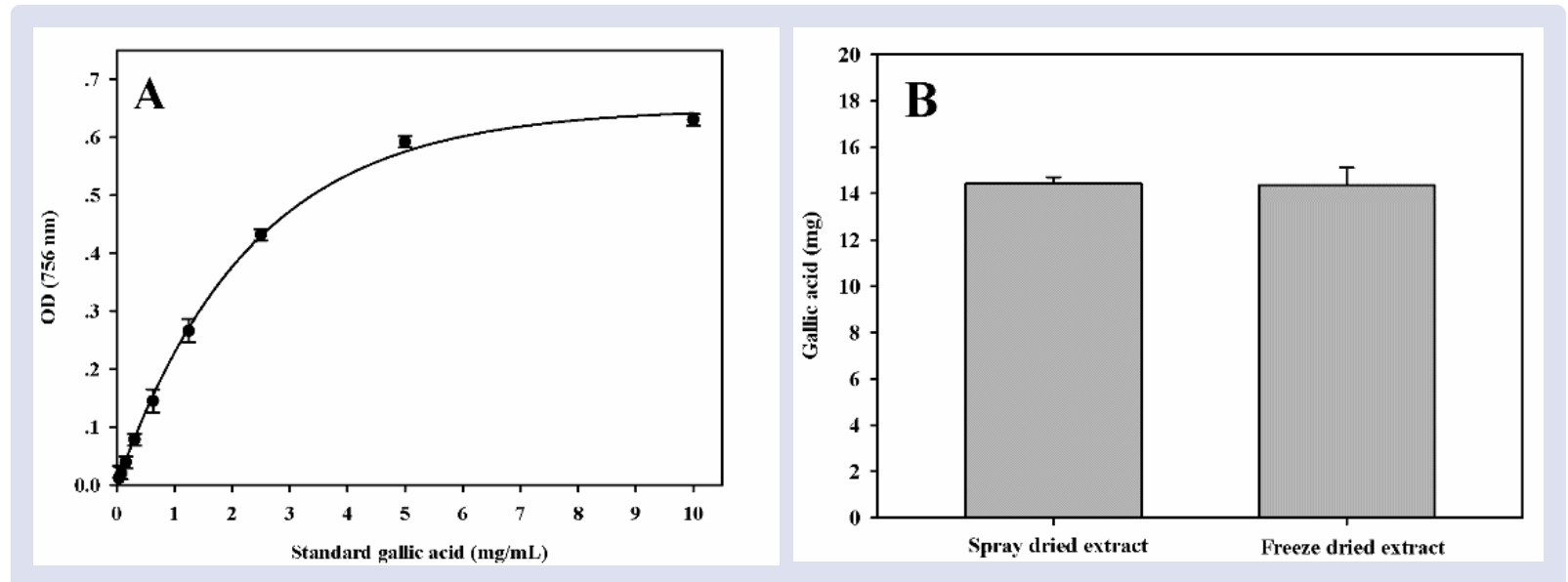

Figure 1: Standard gallic acid $(0.04-10 \mathrm{mg} / \mathrm{mL})(\mathrm{A})$ and total phenolic compounds in spray- and freeze-dried extracts at $1 \mathrm{~g}(\mathrm{~B})$. 


\section{Scavenging activity on the ABTS cation and DPPH radicals of extracts}

The standard gallic acid in the ABTS cation showed the linear response to radical scavenging at $0.0125-0.80 \mathrm{mg} / \mathrm{mL}$ (Figure $4 \mathrm{~A}$ ). The results of scavenging ABTS cation radicals showed that the extracts from spray and freeze drying at $1 \mathrm{~g}$ were significantly different at $14.41 \pm 0.27$ and $14.36 \pm 0.76 \mathrm{mg}$ GAE, respectively (Figure 4B). The standard quercetin in the protocol of the DPPH scavenging method showed that activity rose exponentially at $1.22-78 \mu \mathrm{g} / \mathrm{mL}$, with an IC50 at $23.41 \mu \mathrm{g}$ (Figure 4C). When comparing between extracts, the IC50 was significantly higher in the spray-dried extract $(1.86 \pm 0.56 \mathrm{mg})$ than in the freezedried one (3.77 $\pm 2.5 \mathrm{mg})$ (Figure 4.D).

\section{Manufacturing preparation of hard candy product}

Prior study showed that extract from spray drying had higher nicotine and equal total phenolic compounds to that from the freeze drying technique. Then, the spray-dried extracts were selected for manufacturing into the hard candy product. For preparation on an industrial scale, a large amount of candy was prepared. A previous study of one active smoker showed that $20 \mathrm{~g}$ of VC dry raw materials was mixed in $350 \mathrm{~mL}$ of clean water before boiling and evaporating to $150 \mathrm{~mL}$ of condensed juice, of which a small amount was held in the mouth for 2-3 seconds and drank before smoking. The total amount was limited at $150 \mathrm{~mL}$ per day. The successful effect of VC condensed juice was significant on smoking reduction when used for 2 weeks. The manufacturing process for pilot hard candy products in this study was planned to take 14 days. Therefore, $280 \mathrm{~g}$ ( $20 \mathrm{~g}$ for 14 days) of VC dry raw materials was mixed in $4.9 \mathrm{~L}$ of clean water, and a final condensed juice of $2.1 \mathrm{~L}$ was prepared for spray drying the extract. Finally, 120 hard pieces of candy were made in 4 blister packs (Figure 5).

\section{Total phenolic compounds, total flavonoids and nicotine in hard candy products}

One panel of hard candy contained eight pieces. The weight of each piece was $2.81-3.21 \mathrm{~g}$, with the average weight being $2.99 \pm 0.15 \mathrm{~g}$. Total phenolic compounds were $3.76 \pm 0.72 \mathrm{mg}$ and total flavonoids $0.42 \pm$
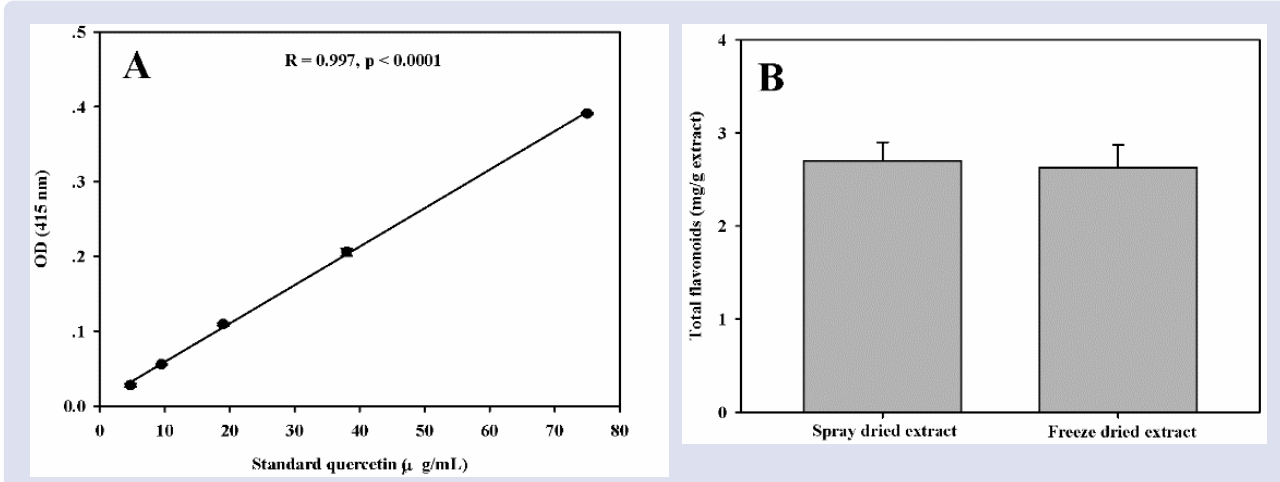

Figure 2: Standard quercetin $(4.7-75 \mu \mathrm{g} / \mathrm{mL})(A)$ and total flavonoids in extracts at $1 \mathrm{~g}(B)$.
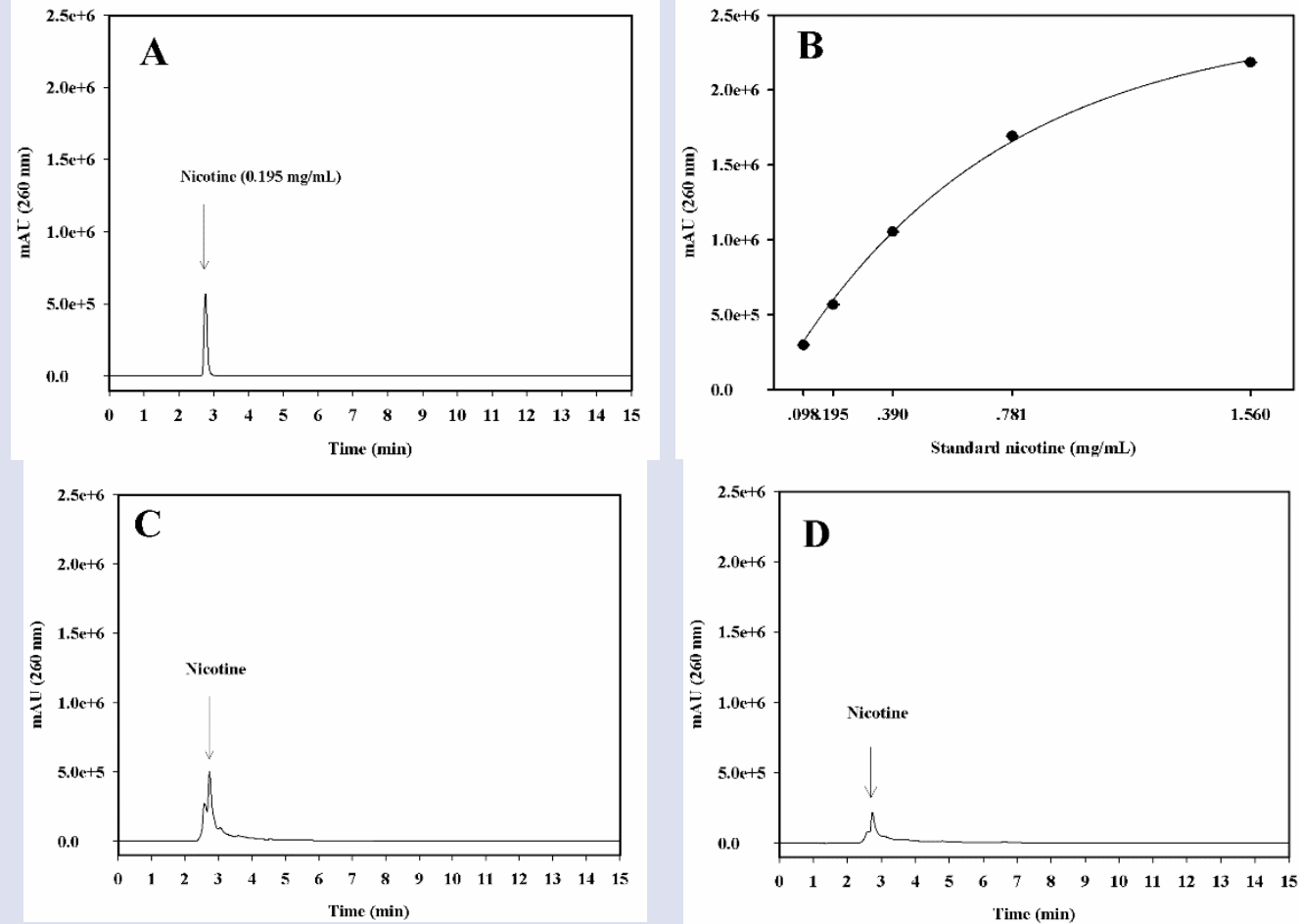

Figure 3: Nicotine peak at $2.67 \mathrm{~min}(\mathrm{~A})$, standard curve of nicotine at $0.098-1.56 \mathrm{mg} / \mathrm{mL}$ (B), nicotine peak of spraydried (C) and freeze-dried extract (D) at $5.0 \mathrm{mg} / \mathrm{mL}$. 

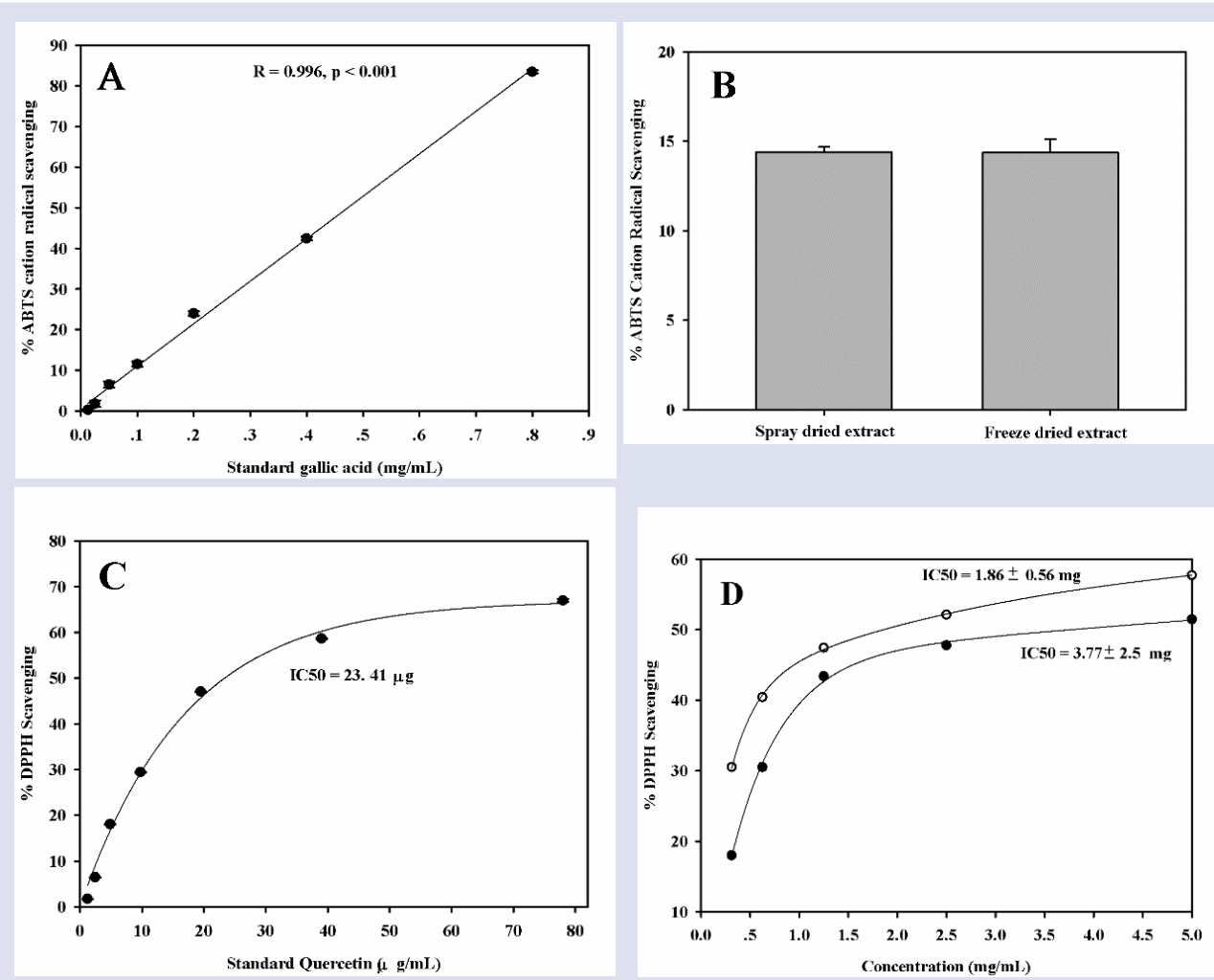

Figure 4: Percentage of scavenging ABTS cation radical of standard gallic acid at $0.0125-0.80 \mathrm{mg} / \mathrm{mL}$ (A), sprayand freeze-dried extracts (B), IC50 on scavenging DPPH radicals of standard quercetin at $1.22-78 \mu \mathrm{g} / \mathrm{mL}$ (C) and between extracts at $5.0 \mathrm{mg} / \mathrm{mL}$ (white circle $=$ spray-dried extract and black circle $=$ freeze-dried extract) $(B)$ and products at $10-80 \mathrm{mg} / \mathrm{mL}$ (black circle $=\mathrm{VC}$ candy and white circle = placebo candy) (D).

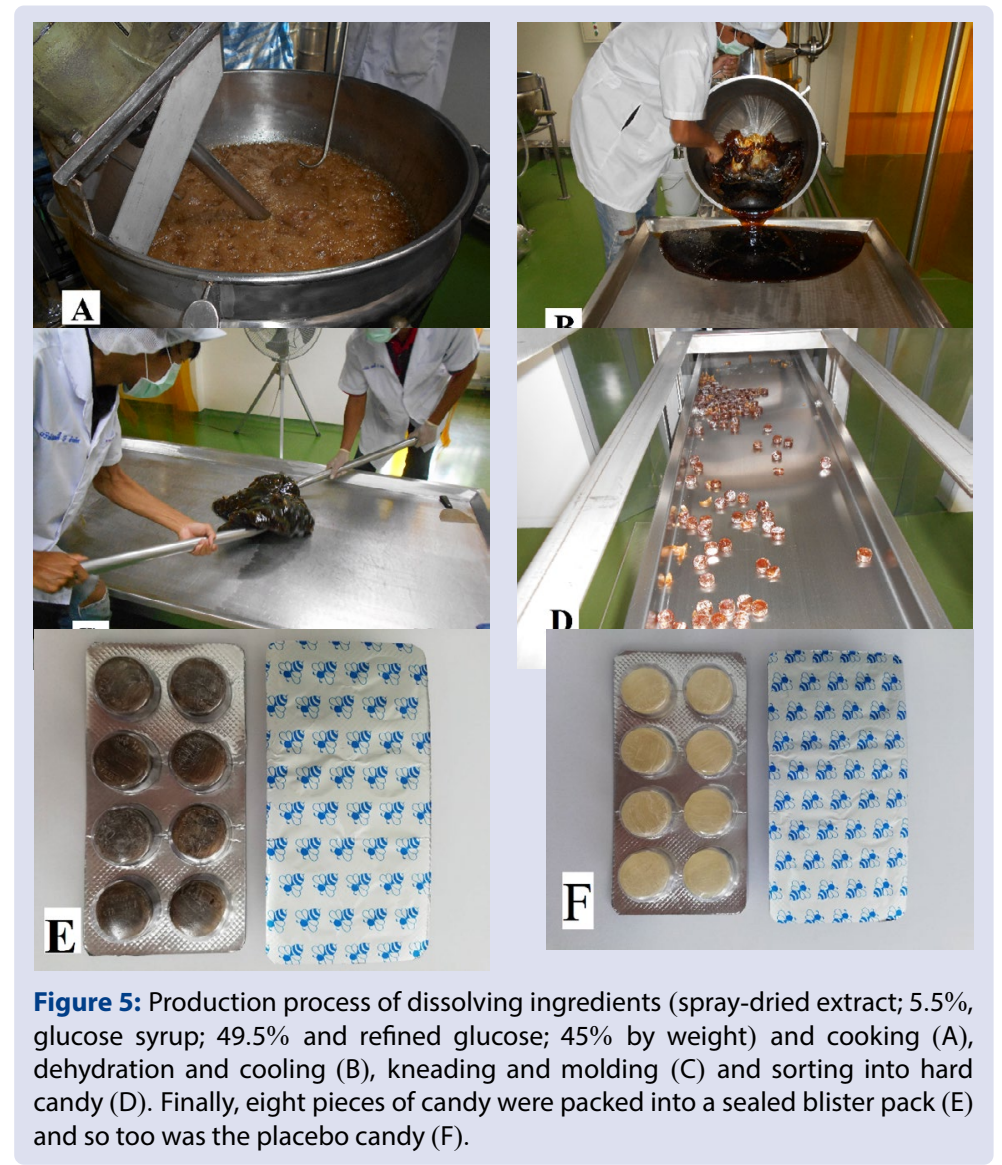


$0.02 \mathrm{mg} /$ piece of hard candy, Moreover, nicotine was $2.35 \pm 0.33 \mathrm{mg}$ per piece of candy (Figure 6A). Whereas, the placebo did not contain total phenolic compounds, total flavonoids or nicotine (Figure 6B).

\section{Scavenging activity on the ABTS cation and DPPH radicals in the hard candy products}

The results of scavenging the ABTS cation radicals in the product responded to a dose of $10-160 \mathrm{mg} / \mathrm{mL}$ (Figure 7A), whereas the placebo showed very a low percentage of ABTS cation radical scavenging (1.21$2.2 \%)$. Then, the scavenging radicals of one piece of hard candy was equal to $2.00 \pm 0.21 \mathrm{mg}$ of gallic acid equivalent (GAE). Scavenging activity on DPPH radicals showed a similar effect on the products (Figure 7B). The IC50 of the product was $48.00 \pm 3.5 \mathrm{mg}$, whereas that of the placebo could not be calculated. Moreover, standard nicotine showed low scavenging activity on DPPH radicals, with dose responses at $10-40 \mathrm{mg} / \mathrm{mL}$. Whereas, no total phenolic compounds or nicotine were present in the placebo candy.

\section{DISCUSSION}

In this study, the safety of raw materials was evaluated and the results showed non-contamination with mercury, however, there was contamination with mercury $(0.019 \mathrm{mg} / \mathrm{kg})$ and zinc $(\mathrm{Zn})(34.42$ $44.36 \mathrm{mg} / \mathrm{kg}$ ). Nevertheless, the policy of the Ministry of Public Health (Thailand) for diet contaminant standards of heavy metals states that content of zinc, mercury and tin in food must be less than $100 \mathrm{mg} / \mathrm{g}$, $250 \mathrm{mg} / \mathrm{g}$ and $20 \mathrm{mg} / \mathrm{g}$, respectively (FDA Announcement, 2018, Thailand). ${ }^{24}$ Therefore, the raw VC materials in this study were safe for modification as an anti-smoking aid for humans.

This preliminary study showed different contents of total phenolic compounds, total flavonoids and nicotine in extracts from two preparative techniques. There was an insignificant difference between both extracts that were prepared by following the Thai traditional guideline of mixing $20 \mathrm{~g}$ of raw dry $\mathrm{VC}$ materials in 3 cups of clean water before braising for the final $150 \mathrm{~mL}$ of condensed juice. ${ }^{12}$ Previous study researched different parts of VC extracts. Catechins such as epicatechin gallate (ECG) $(12.42 \pm 1.13 \mathrm{mg})$, epicatechin (EC) $(35.12 \pm 1.34 \mathrm{mg})$, epigallocatechin gallate (EGCG) $(16.11 \pm 0.98 \mathrm{mg})$ and C $(165.23 \pm 1.22$ $\mathrm{mg}$ ) were presented dominantly in freeze-dried leaf of VC extract at 1 $\mathrm{g}$, as the same for flavonoids (197.07 $\pm 4.05 \mathrm{mg}$ of myricetin and 113.6 $\pm 5.67 \mathrm{mg}$ of quercetin). ${ }^{14}$ Total phenolic compounds had a very high concentration in leaf extract $(669.2 \pm 17.2 \mathrm{~g} / \mathrm{g}$ extract), when compared to that in the stem $(123.5 \pm 14.4 \mathrm{~g})$ and flower $(179.5 \pm 11.3 \mathrm{~g}) .^{15}$ Whereas, a previous study showed total phenolic compounds in crude VC ethanolic-extract being very high $(179.86 \pm 3.55 \mathrm{mg} / \mathrm{dried}$ weight $)$ when compared to those in green tea (Camellia sinensis L) $(109.79 \pm$ $2.89 \mathrm{mg} / \mathrm{g}$ dried weight). ${ }^{25}$

Furthermore, the analysis of nicotine concentration in extracts from spray and freeze drying at $1 \mathrm{~g}$ was $28.99 \pm 0.28 \mathrm{mg}$ and $26.82 \pm 0.32$
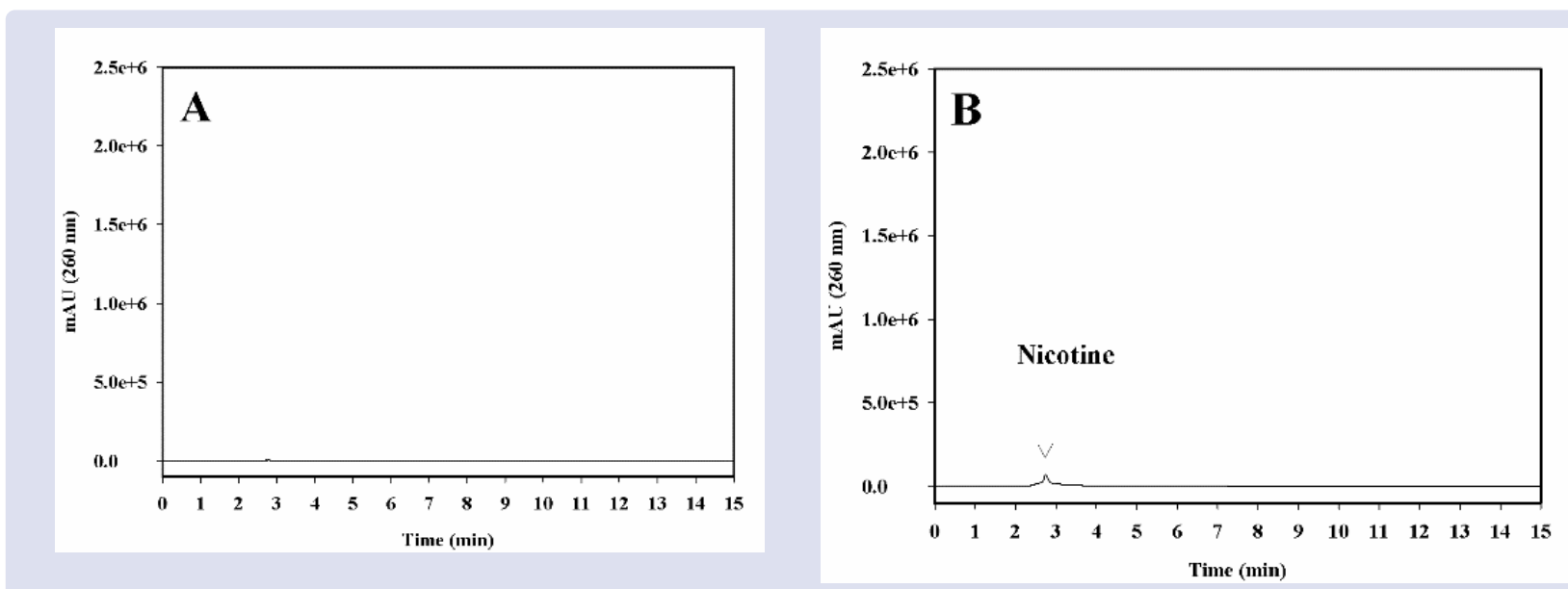

Figure 6: HPLC results of the hard candy placebo $(50 \mathrm{mg} / \mathrm{mL})(A)$ and nicotine peak in the hard candy product $(50 \mathrm{mg} / \mathrm{mL})(B)$.
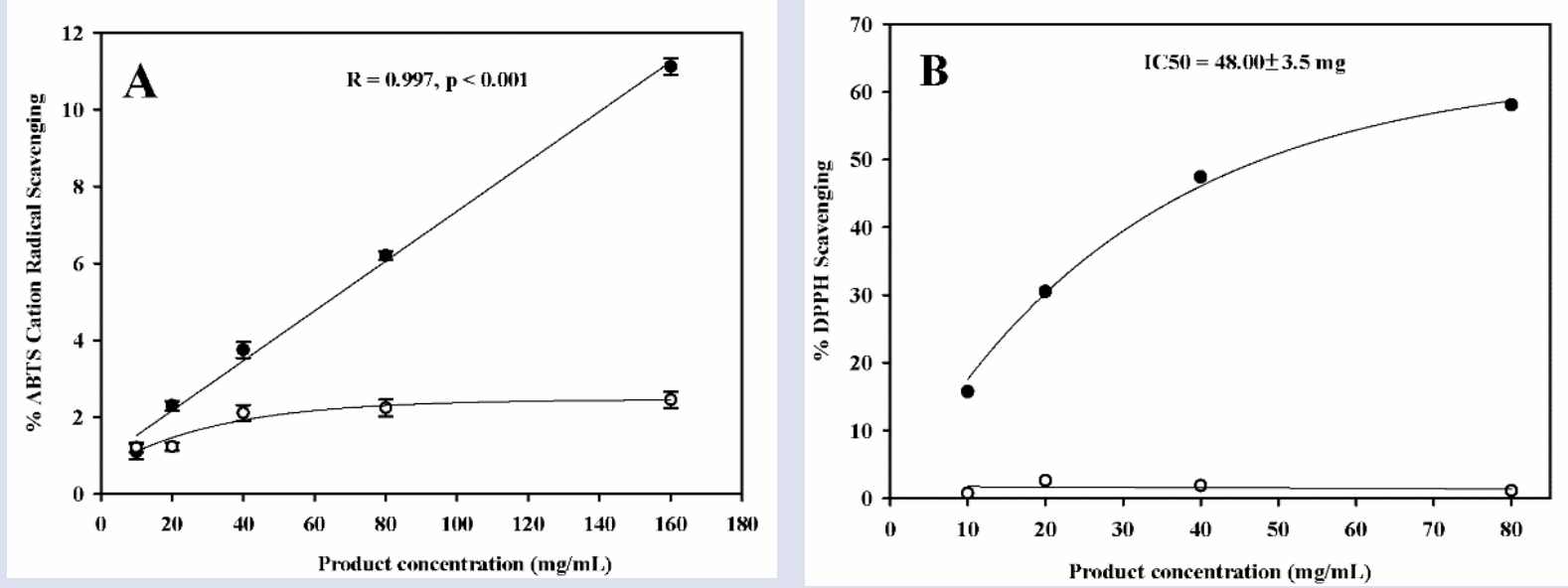

Figure 7: Percentage of ABTS cation radical scavenging between the product and placebo at $10-160 \mathrm{mg} / \mathrm{mL}(\mathrm{A})$ and the IC50 of the products that contained spray-dried extract, glucose syrup and refined glucose (B) (black circle $=$ VC candy and white circle $=$ placebo candy). 
$\mathrm{mg}$, respectively, with insignificant difference. However, a previous study found lower nicotine concentration in flower $(1.23 \pm 0.11 \mathrm{mg} / \mathrm{g}$ extract) and leaf extract $(1.54 \pm 0.14 \mathrm{mg} / \mathrm{g}$ extract) from freeze drying. ${ }^{14}$ Nevertheless, the total phenolic compounds and nicotine in whole parts of VC materials in this study could not compare with those in the previous one. ${ }^{14,15}$ In addition, a previous study of crude ethanolic-extract of VC showed a lower concentration of nicotine $(1.154 \pm 0.38 \mathrm{mg} / \mathrm{g}$ extract $)^{25}$, which can be explained by different extract preparations and varied purchases of raw materials. Although previous evidence showed different concentrations of nicotine, total phenolic compounds and antioxidant scavenging activity, it was confirmed that VC extract has potential as an anti-smoking aid in the future. Moreover, two different preparative techniques; freeze and spray drying, showed insignificant contents of total phenolic compounds, total flavonoids and nicotine.

When comparing the antioxidant capacity by evaluating scavenging ABTS cation and DPPH radicals, the results presented similar activity between the extracts $(14.41 \pm 0.27$ and $14.36 \pm 0.76 \mathrm{mg} \mathrm{GAE}$, respectively, at $1 \mathrm{~g}$ of extract). However, the results on scavenging DPPH radicals showed that spray-dried extract had higher IC50 (1.86 $\pm 0.56 \mathrm{mg})$ than freeze-dried extract $(3.77 \pm 2.5 \mathrm{mg})$. Although the dominantly antioxidant activity results were in spray-dried extract from whole VC parts, the freeze dried-extract also showed its activity, which was supported by a previous study. ${ }^{15}$ The leaf extract showed a protective effect on glutathione (GSH) and lipid peroxide formation in red blood cells from 2,2'-azobis(2-amidinopropane) dihydrochloride (AAPH), due to the highest total of phenolic compounds. Whereas, the antioxidant activity of each VC extract part showed that leaf extract had the highest scavenging activity on 2,2'-azino-bis (3-ethylbenzthiazoline6-sulphonic acid) (ABTS) cation radicals. The stem extract showed higher activity on scavenging nitric oxide (NO) and superoxide $\left(\mathrm{O}_{2}\right.$ ), and the flower extract was dominant in scavenging activity on the hydroxyl radical $(\mathrm{OH}) .{ }^{15}$

This is still an unclear mechanism because of the insignificant contents of the total phenolic compounds in both extracts, but slightly higher nicotine in the spray-dried extract possibly affects the DPPH scavenging results. Standard nicotine was co-evaluated in prior experiments on ABTS and DPPH scavenging activity, and results confirmed that it had low scavenging activity on ABTS radicals at $7.11 \pm 0.2 \%$ of 10 $\mathrm{mg} / \mathrm{mL}$ and $14.60 \pm 2.3 \mathrm{mg} / \mathrm{mL}$ of $20 \mathrm{mg} / \mathrm{mL}$, whereas the capacity of scavenging DPPH radicals was very low (2.5-5.0\%) and did not respond to doses of $2.5-20 \mathrm{mg} / \mathrm{mL}$ of standard nicotine. This result was in contrast to a previous study by claiming that the mechanism of its antioxidant activity acted as a radical scavenger by binding with iron, ${ }^{26}$ and nicotine alkaloids were able to scavenge DPPH radicals as well as protect erythrocytes from AAPH- and tert-Butyl hydroperoxide $(\mathrm{BuOOH})$-induced oxidative haemolysis. ${ }^{27}$ Therefore, it is possible that the contrasting result is preferred to different protocols.

Although there have been many products such as lozenges, gum and patches, the pilot VC product was designed with hard candy at the Healthy Bee Co., Ltd. (Chiang Mai, Thailand) because of the vast experience this company has with hard candy production under the Certificate $\mathrm{TH}$ 14/7924 (TAS 9023-2007) GMP Codex Alimentarius, Recommended International Code of Practices, General Principles of Food Hygience, CAC/RCP 1-1969, Rev.4 (2003). The product was manufactured industrially as a pilot hard candy with three main ingredients (spraydried extract; $5.5 \%$, glucose syrup; $49.5 \%$ and refined glucose; $45 \%$ by weight). Spray-dried extract was selected for manufacturing this product because of its low-cost and short preparation time for drying. A large amount of candy has been prepared on an industry scale. In a previous study of one active smoker, $20 \mathrm{~g}$ of VC dry raw materials was mixed in $350 \mathrm{~mL}$ of clean water before boiling and evaporating to 150 $\mathrm{mL}$ of condensed juice. Then, the $150 \mathrm{~mL}$ of condensed juice was used by holding a small amount in the mouth for 2-3 seconds and drinking it before smoking. The amount was limited to $150 \mathrm{~mL}$ per day. The effect of VC condensed juice significantly reduced smoking when used for 2 weeks. ${ }^{12}$ The pilot hard candy produced at the Healthy Bee Co., Ltd was packed in a panel, which contained eight pieces of candy. The weight of one piece was 2.81-3.21 g, with an average weight of $2.99 \pm$ $0.15 \mathrm{~g}$ per piece. The total phenolic compounds and total flavonoids in one piece of hard candy were $3.76 \pm 0.72 \mathrm{mg}$ and $0.42 \pm 0.02 \mathrm{mg}$, respectively. Therefore, the total phenolic compounds in one panel of hard candy was approximately $26.37 \mathrm{mg}$ and $2.35 \pm 0.33 \mathrm{mg}$ of nicotine per piece of candy. Previous evidence showed that nicotine use varied depending on the products; such as transdermal patches (5-52.5 mg over a 24 -hour period) ${ }^{28}$ nicotine gum ( 2 and $\left.4 \mathrm{mg}\right)$, nasal sprays ( 0.5 or $1.0 \mathrm{mg}$ per spray), nicotine inhalator (10 and $15 \mathrm{mg}$ ), nicotine lozenges $(1,1.5,2$ and $4 \mathrm{mg}$ strength) and nicotine sublingual tablets ( $3 \mathrm{mg}$ dose),${ }^{29}$ and the efficacy of nicotine patches has been studied extensively. ${ }^{30-32}$ Therefore, this preliminary study showed the dominantly active compounds in VC extract that were prepared by using the spray-dried technique, and a new nicotine-contained hard candy can be manufactured, containing approximately $2.35 \pm 0.33 \mathrm{mg}$ of nicotine per piece and a total of $18.80 \mathrm{mg}$ over a 24-hour period, which is not above the previous guideline. ${ }^{28}$ However, this product must be evaluated further in human smokers, in order to confirm its efficacy on smoking rate, and also human safety.

\section{CONCLUSION}

This preliminary study summarized development of a natural plant for the reduction of smoking, with doses of an increased concentration of VC, which was boiled and spray-dried. The pilot product model of hard candy is one of many processes for development in this industry. The possible benefit of smoking reduction may involve preserving nicotine that can reduce withdrawal symptoms.

\section{ACKNOWLEDGEMENTS}

This study was supported by the Faculty of Associated Medical Sciences, Chiang Mai University, Chiang Mai, Thailand.

\section{ABBREVIATION}

FD: Freeze dry, SD; Spray dry, VC; Vernonia cinerea, GAE: Gallic acid equivalent; DPPH; 1,1-diphnyl-2-picrylhydrazyl, IC50: Half-maximal inhibitory concentration.

\section{REFERENCES}

1. Perez-Warnisher MT, Carballosa de Miguel, M. del P, Seijo LM. Tobacco Use Worldwide: Legislative Efforts to Curb Consumption. Ann Glob Health. 2019;85(1):9.

2. Benjakul S, Jangkapanich A, Temsirikulchai L, Tadkayun N, Nakju S. Situation of smoking consumption in Thai Population from 1991-2007. Tobacco control research and knowledge management center. (Report). Bangkok. 2008:1-IV.

3. Hoffman SJ, Poirier MJP, Katwyk SRV, Bara P, Sritharan L. Impact of the WHO Framework Convention on Tobacco Control on global cigarette consumption: quasi-experimental evaluations using interrupted time series analysis and insample forecast event modelling. BMJ. 2019;365:12287.

4. Rungruanghiranya S, Ekpanyaskul C. Impact of tobacco control campaigns on smoking behaviors in Thai medical schools. J Med Assoc Thai. 2017;100(3):339 46.

5. Fiore MC, Bailey WC, Cohen SJ. Treating tobacco use and dependence. Clinical Practice Guideline. Rockville (MD): US Department of Health and man Service, Public Health Service: 2008.

6. Stead LF, Perera R, Bullen C, Mant D, Hartmann-Boyce J, et al. Nicotine replacement therapy for smoking cessation. Cochran Database Sys Rev.2012;11:CD000146.

7. Prochazka AV. New developments in smoking cessation. Chest. 2000;117(Supp 1):169-75

8. Bertram MY, Lim SS, Wallace AL, VosT. Costs and benefits of smoking cessation aids: making a case for public reimbursement of nicotine replacement therapy in Austraila. Tob Control. 2007;16(14):255-60. 
9. Mills EJ, Wu P, Lockhart I, Wilson K, Ebber JO. Adverse events associated with nicotine replacement therapy (NRT) for smoking cessation. A systematic review and meta-analysis of one hundred and twenty studies involving 177, 390 individuals. Tob Induc Dis. 2010;8:8.

10. Lee $\mathrm{HJ}$, Lee $\mathrm{JH}$. Effects of medicinal herb tea on the smoking cessation and reducing smoking withdrawal symptoms. Am J Chin Med. 2005;33(1):127-38.

11. Wongwiwatthanaukit S, Benjanakaskul P, Songsak T, Suwanamajo S, Verachai V. Efficacy of Vernonia cinerea for smoking cessation. J Health Res. 2009;23:31-6.

12. Leelarungrayub D, Pratanaphon $S$, Pothongsunun $P$, Sriboonreung T, Yankai $A$ Bloomer RJ. Vernonia cinerea Less. supplementation and strenuous exercise reduce smoking rate: relation to oxidative stress status and beta-endorphin release in active smokers. J Int Soc Sports Nutrition. 2010;7:21.

13. Prasopthum A, Pouyfung P, Sarapusit S, Srisook E, Rongnoparut P. Inhibition effects of Vernonia cinerea active compounds against cytochrome P450 2A6 and human monoamine oxidase, possible targets for reduction of tobacco dependence. Drug Metab Pharmacokinet. 2015;30:174-81

14. Ketsuwn N, Leelarungrayub J, Kothan S, Singhatong S. Antioxidant compounds and activities of the stem, flower, and leaf extracts of the anti-smoking Thai medicinal plant: Vernonia cinerea Less. Drug Des Devel Ther. 2017;11:381 91(A).

15. Kesuwan N, Leelarungrayub J, Banchonglikitkul C. Effect of Thai medicinal plant, Vernonia cinerea Less, extract on catecholamine, oxidative stress and chromosome aberration in nicotine-treated rats. J Assoc Med Sci. 2017;50(2):262-74.

16. Emami F, Vatanara A, Park EJ, Na DH. Drying technologies for the stability and bioavailability of biopharmaceuticals. Pharmaceutics. 2018;10(3):131

17. Abdul-Fattah AM, Kalonia DS, Pikal MJ. The challenge of drying method selection for protein pharmaceuticals: product quality implications. J Pharm Sci. 2007;96(8):1886-916.

18. Sosnik A, Seremeta KP. Advantages and challenges of the spray-drying technology for the production of pure drug particles and drug-loaded polymeric carriers. Adv Colloid Interface Sci. 2015;223:40-54.

19. Singleton VL, Rossi JA Jr. Colorimetry of total phenolics with phosphomolybdicPhosphotungstic acid reagents. Am J Enol Vitic. 1965;16:144-58.
20. Sembiring EN, Elya B, Sauriasari R. Phytochemical screening, total flavonoid and total phenolic content and antioxidant activity of different parts of Caesalpinia bonduc (L.) Roxb. Pharmacogn J. 2018;10: 123-7.

21. Pankow JF, Kim K, McWhirter KJ, Luo W, Escobedo JO, Strongin RM, et al Benzene formation in electronic cigarettes. PLosOne. 2017.

22. Re R, Pellegrini N, Proteggente A, Pannala A, Yand M, Rice-Evans C. Antioxidan activity applying an improved ABTS radical cation decolorization assay. Free Radic Bio Med. 1999;26:1231-7.

23. Brand-Williams W, Cuvelier ME, Berset C. Use of free radical method to evaluate antioxidant activity. Lebens- Wiss Technol. 1995;28:25-30.

24. Diet contaminant standards, FAD Announcement, Ministry of Public health Thailand. 2018.

25. Naijitra C, Cheoymant A. Evaluation of antioxidant activity, total phenolic and nicotine contents of 15 Thai herbs. J Sci Technol. 2017;24(2):351-61.

26. Newman MB, Arendash GW, Shytle RD, Bickford PC, Tighe T, Sanberg PR. Nicotine's oxidative and antioxidant properties in CNS. Life Sci. 2002;71(24):2807-20.

27. Jaskola KM, Jasiewicz B, Mrowczynska L. Nicotine alkaloids as antioxidant and potential protective against in vitro oxidative haemolysis. Chemico Biol Inter. 2016;243:62-71

28. Fiore MC, Jorenby DE, Baker TB, Kenford SL. Tobacco dependence and the nicotine patch. Clinical guidelines for effective use. JAMA. 1992;268:2687-94.

29. Boyce JH, Chepkin SC, Ye W, Bullen C, Lancaster T. Nicotine replacement therapy versus control for smoking cessation. Cochrane Database Syst Rev. 2018;2018(5):CD000146.

30. Burns EK, Hood NE, Goforth E, Levinson AH. Randomised trial of two nicotine patch protocols distributed through a state quitline. Tob Control. 2016;25(2):218-23.

31. Caldwell BO, Adamson SJ, Crane J. Combination rapid-acting nicotine mouth spray and nicotine patch therapy in smoking cessation. Nicotine Tob Res. 2014:16(10):1356-64.

32. Dale LC, Hurt RD, Offord KP Lawson GM, Croghan IT, Schroeder DR, Highdose nicotine patch therapy - percentage of replacement and smoking cessation. JAMA. 1995;274(17):1353-8.

\section{GRAPHICAL ABSTRACT}

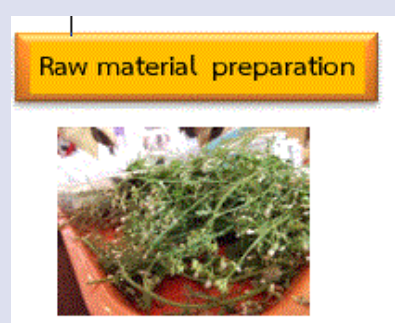

Vernonia cinerea (VC)
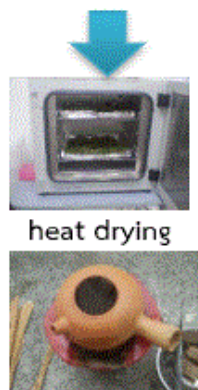

boiling

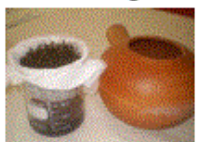

condensed VC juice

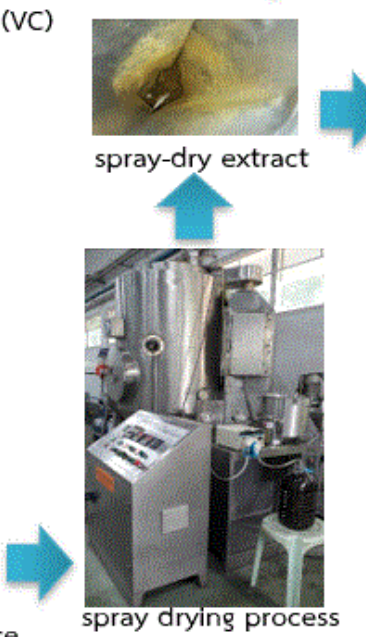

Extract preparation

Active compounds assay and Antioxidant test

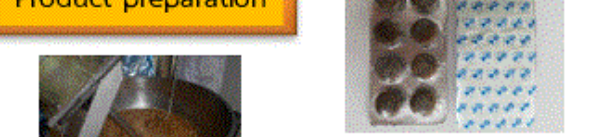

VC hard candy packaging

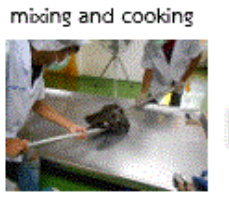

dehydration and cooling kneading and moldings
Setting the shape of candy

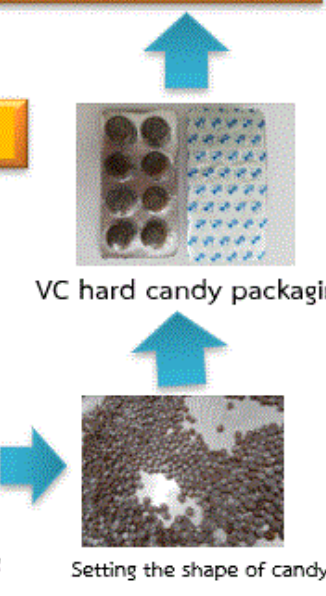




\section{ABOUT AUTHORS}

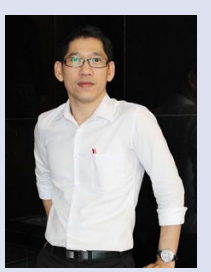

JIRAKRIT LEELARUNGRAYUB: Associate professor of Physical Therapy (PT), Faculty of Associated Medical Sciences (AMS), Chiang Mai University (CMU), Thailand. He received a Bachelor of Sciences (BSc.PT) from Faculty of AMS, Khon Kaen University, Master of Sciences (MS.c) and Ph.D. degrees (Biochemistry) from Faculty of Medicine, CMU. Specialized researches on cardiopulmonary rehabilitation, nutrition and sports, exercise sciences and natural products for health related to oxidative stress and inflammation in vitro and in human or patient. More than 30 research and review articles were published in international journal or books.

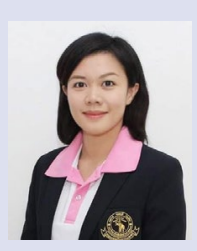

RUNGTIWA KANTHAIN: Bachelor Degree in Physical Therapy from Faculty of AMS, CMU in 2008.She has excellent experience in cardiopulmonary physiotherapy. Currently studying in the Master degree program of Movement and Exercise Sciences under supervised by Associate Prof. Jirakrit Leelarungrayub at Faculty of AMS, CMU, Thailand.

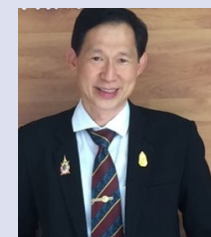

SURAPOL NATAKANKITKUL: Associate professor of Pharmaceutical Sciences, Faculty of Pharmacy, CMU. He received his B.Pharm from Faculty of Pharmacy, CMU. M.Pharm (Clinical and Hospital Pharmacy) from Faculty of Pharmaceutical Science, Chulalongkorn University, Bangkok. In 1991 he received Dr.rer.nat. in Biotechnology and Analytical Chemistry from Innsbruck University, Austria. Research field: Pharmaceutical science, pharmacology, toxicology and phytocosmetics. More than 30 research articles were published in international journals. Supervision of 15 master degrees and $8 \mathrm{PhD}$ degrees of academic thesis. Now, he is the president of the Society of Cosmetic Chemists of Thailand.

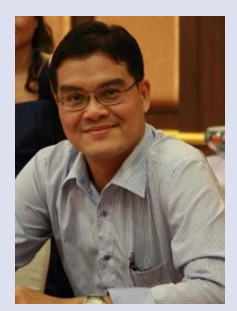

SUPAWATCHARA SINGHATONG: Assistant Professor of Medical Technology, Division of Clinical Chemistry, Department of Medical Technology, Faculty of AMS, CMU. He received his B.Sc. (Medical Technology) from Faculty of AMS, CMU. M.Sc. (Toxicology) from Department of Forensic Medicine, Faculty of Medicine, CMU, and Ph.D. of Pharmacy from Faculty of Pharmacy, CMU, Thailand. Research field: toxicology, antioxidant and anti-inflammation.

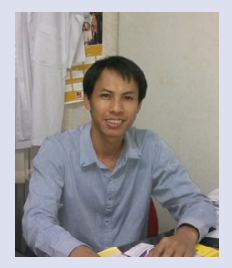

NATHUPAKORN DECHSUPA: Assistant Professor at Department of Radiologic Technology, Faculty of Associated Medical Sciences, Chiang Mai University. In 2006 Dr. Nathupakorn earned his Ph.D. in Biomedical Sciences from Chiang Mai University. His research experience covers molecular imaging, biophysics, natural products, and drug discovery, cancer biology, and therapy. Research interests include molecular imaging and theranostic probes development from natural products apply in cancer diagnostic and treatment.

Cite this article: Kanthain R, Singhatong S, Natakankitkul S, Dechsupa N, Leelarungrayub J. Potential of Hard Candy Containing Spray-Dried Vernonia cinerea Extract with Total Phenolic Compounds, Total Flavonoids and Nicotine Replacement as an AntiSmoking Aid. Pharmacog J. 2020;12(1):35-43. 